\title{
DÜBLIN
}

Technological University Dublin

ARROW@TU Dublin

Articles

School of Food Science and Environmental

Health

2011-10

\section{Nonthermal Plasma Inactivation of Food-Borne Pathogens}

\author{
N. Misra \\ Technological University Dublin, misra.nrusimhanath@tudublin.ie \\ B. Tiwari \\ Manchester Metropolitan University, b.tiwari@mmu.ac.uk \\ K. Rahavarao \\ Council for Scientific and Industrial Research (CSIR) India
}

See next page for additional authors

Follow this and additional works at: https://arrow.tudublin.ie/schfsehart

Part of the Food Processing Commons

\section{Recommended Citation}

Tiwari, B.K. (2011) Nonthermal Plasma Inactivation of Food-Borne Pathogens. Food Engineering Reviews, Vol. 3, No. 3-4 (2011), 159-170. doi:10.1016/j.jhazmat.2015.07.061

This Article is brought to you for free and open access by the School of Food Science and Environmental Health at ARROW@TU Dublin. It has been accepted for inclusion in Articles by an authorized administrator of ARROW@TU Dublin. For more information, please contact arrow.admin@tudublin.ie, aisling.coyne@tudublin.ie, gerard.connolly@tudublin.ie.

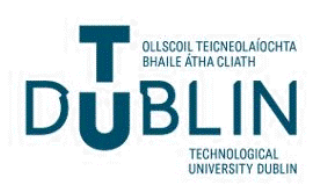


Authors

N. Misra, B. Tiwari, K. Rahavarao, and Patrick Cullen

This article is available at ARROW@TU Dublin: https://arrow.tudublin.ie/schfsehart/94 


\title{
Nonthermal Plasma Inactivation of Food-Borne Pathogens
}

\author{
N. N. Misra ${ }^{\text {a }}$, B. K. Tiwari ${ }^{\text {b* }}$, K. S. M. S. Raghavarao ${ }^{\text {c }}$ P. J. Cullen ${ }^{\text {a }}$ \\ ${ }^{\text {a }}$ School of Food Science \& Environmental Health, Dublin Institute of \\ Technology, Dublin 1, Ireland \\ ${ }^{\mathrm{b}}$ Manchester Food Research Centre, Manchester Metropolitan University, \\ Manchester, M14 6HR, UK \\ ${ }^{\mathrm{c}}$ Department of Food Engineering, Central Food Technological Research \\ Institute, Council for Scientific and Industrial Research (CSIR), \\ Mysore - 570 020, India
}

* Corresponding Author:

Brijesh Tiwari; b.tiwari@mmu.ac.uk, Tel: +441612472178 


\begin{abstract}
Non-thermal plasma (NTP) is electrically energized matter, composed of highly reactive species including gas molecules, charged particles in the form of positive ions, negative ions, free radicals, electrons and quanta of electromagnetic radiation (photons) at near-room temperature. NTP is an emerging nonthermal technology with potential applications for decontamination in the food industries. An upsurge in the research activities for plasma based inactivation of food borne pathogens is evident in the recent years. These studies have shown that NTP can be used for the surface decontamination of raw produce, dried nuts and the packaging materials etc. This paper reviews the action of plasma agents on the microbial classes and describes proven and potential applications in food processing. Novel developments in the technology and a future outlook for the application to foods are discussed.
\end{abstract}

\title{
Keywords
}

Nonthermal, plasma, sterilization, decontamination, food 


\section{Introduction}

Ensuring safe and quality food has become more complex task today, than at any point of time in the history. New risks are being encountered because of changing characteristics of the relevant micro-organisms, changing production methodologies, changes in the environment and the ecology, and an increase of the global trade of food stuffs (Havelaar et al. 2010). As consumer demands and food safety issues have changed, so have the food processing technologies (Gould 2001) to ensure food safety. Moreover, there are multiple issues relating to quality of thermally processed foods such as nutritional losses and adverse effects on organoleptic quality. This has led to the emergence of so called "Nonthermal Technologies" (Sampedro et al. 2005). Nonthermal technologies are preservation treatments that are effective at ambient or sub-lethal temperatures, thereby minimizing negative thermal effects on nutritional and quality parameters of food (Tiwari et al. 2009). These include the application of gamma irradiation, beta irradiation (electron beam), power ultrasound, ozonation, pulsed light, UV treatment, pulsed electric field (PEF), high hydrostatic pressure etc. Nevertheless, even some of these commercially viable inactivation methods are limited in practice due to adverse perceptions associated (like with treatments of gamma irradiation and high energy electron beams) or high initial investments required and/or other constraints. Purely physical techniques, such as high hydrostatic pressure, are chemically safe but require complex or expensive equipment (Rastogi et al. 2007), affect the quality of the product (Kruk et al. 2009) and are generally incompatible with online treatments. Very few approaches are suitable for treatment of solid foods, in particular fruit and vegetables. Very recently NTP has been added to the existing list of non-thermal processes for the decontamination of fresh produce (Critzer et al. 2007; Niemira and Sites 2008; Lee et al. 2006).

Technologies like UV treatment, ozonation, power ultrasound, pulsed light, electric discharge and nonthermal plasma are commonly designated as Advanced Oxidation Processes (AOP). The use of pulsed UV light as a means of microbial inactivation is a mature technology that has commercial application in surface disinfection of packaging materials, but demonstrates limitations due to shadowing effects in food products (Gómez-López et al. 2007). Indeed, there is currently no perfect method to achieve sterilization at ambient temperature. NTP or cold plasma, which has recently 
drawn considerable attention of the food scientists and researchers (Vleugels et al. 2005; Basaran et al. 2008; Selcuk et al. 2008), forms the subject of this paper. This paper reviews the applications of nonthermal plasma techniques for inactivation of food borne pathogens, proposed mechanisms underlying microbial inactivation and spore destruction, while discussing limitations and scope for future studies.

\section{Plasma Science}

\section{Plasma- Definition, Physics and Chemistry}

In 1922, the American scientist Irving Langmuir proposed that the electrons, ions and neutrals in an ionized gas could be considered as corpuscular material entrained in some kind of fluid medium and termed this entraining medium "plasma", similar to the plasma, introduced by the Czech physiologist Jan Evangelista Purkinje to denote the clear fluid which remains after removal of all the corpuscular material in blood. However, it emerged that there was no "fluid medium" entraining the electrons, ions, and neutrals in an ionized gas (Bellan 2006), nevertheless the name prevailed.

The term "plasma" refers to a partially or wholly ionized gas composed essentially of photons, ions and free electrons as well as atoms in their fundamental or excited states possessing a net neutral charge. The plasma possesses a net neutral charge because the number of positive charge carriers is equal to the number of negative ones (Kudra and Mujumdar 2009). Electrons and photons are usually designated as "light" species in contrast to the rest of the constituents designated as "heavy" species. Due to its unique properties plasma is often referred to as the fourth state of matter according to a scheme expressing an increase in the energy level from solid to liquid to gas and ultimately to plasma.

\section{Types of Plasma}

Two classes of plasma, namely thermal and NTP can be distinguished on the basis of conditions in which they are generated. This classification of plasma is based on the relative energetic levels of electrons and heavy species of the plasma. NTP (near ambient temperatures of $30-60^{\circ} \mathrm{C}$ ) is obtained at atmospheric or reduced pressures 
(vacuum) and requires less power. NTPs are characterised by an electron temperature much above that of the gas (macroscopic temperature) and consequently do not present a local thermodynamic equilibrium. NTP can be generated by an electric discharge in a gas at lower pressure or using microwaves. Typical illustrations for plasma generation at atmospheric pressure include the corona discharge, Dielectric barrier discharges (DBD), Radio-frequency plasmas (RFP) and the gliding arc discharge. In contrast, thermal plasmas are generated at higher pressures, require high power, and an almost thermal equilibrium exists between the electrons and the heavy species. Plasma generation at atmospheric pressure is of interest, both technically and industrially for the food industries because this does not require extreme conditions.

\section{Plasma Sources}

Formerly, plasma treatments were carried out under vacuum conditions, but researchers have now developed atmospheric pressure plasma system, resulting in reduced cost, increased treatment speed, and industrial applicability (Yoon and Ryu 2007; Yun et al. 2010). The ability to generate non-thermal plasma discharges at atmospheric pressure makes the decontamination process easier and less expensive (Kim et al. 2011). However, until very recently, most of the cold plasma devices available commercially were developed for research and aimed at biomedical applications. Therefore, for food applications, these devices may need to be customized or tailor made. The barrier glow discharge generated between two parallel electrodes is a widely employed NTP system. In a possible industrial scale set-up, food may be conveyed through the discharge to achieve microbial decontamination. Another configuration is the plasma pen or jet, in which a stream of gases can be directed at the object to be treated. Biozone Scientific has developed a new process for the generation of cold oxygen plasma (COP) by subjecting air to high- energy deepUV light with an effective radiation spectrum between $180 \mathrm{~nm}$ and $270 \mathrm{~nm}$. This cold gas plasma is composed of several species like negative and positive ions, free radical molecules, electron, UV-photons and ozone (Terrier et al. 2009). Duo-Plasmaline is a linearly extended plasma source excited using microwaves of $2.45 \mathrm{GHz}$ at a pressure $<1000 \mathrm{~Pa}$ (Petasch et al. 1997) and several other plasma treatment systems have evolved based on this principle. The Plasmodul is a microwave sustained low pressure plasma reactor with a modular concept based on the Duo-Plasmaline principle which 
provides an easy upscaling for industrial applications (Schulz et al.). This type of microwave excited plasma sources are well suited for large area plasma treatment (Petasch et al. 1997) and can probably be employed for surface treatment of foods or processing surfaces at industrial scale. More recently, Kim et al. (2010) developed a cold plasma jet operating at $20 \mathrm{kHz}$ Alternating Current (AC) under atmospheric pressure. The most versatile feature of most of the plasma systems is the freedom to select a gas or gas mixture. Improvements in the existing plasma systems and newer equipment directed for treatment of real food systems are likely to draw attention of researchers and engineers in near future.

Recently a novel approach which shows significant potential for the treatment of various foods has been reported. The approach is based on a dielectric barrier discharge with the food package in contact with high voltage electrodes. Only 40-50 $\mathrm{W}$ of power is needed to ionize air inside a $4 \mathrm{~L}$ re-sealable plastic (LDPE) bag (Klockow and Keener 2009). The high voltage process ionizes any gas within the electric field contained within the package. Ionization can generate significant amounts of reactive molecules with little increase in product surface temperature. Specific treatment times for targeted spore or bacterial reductions are dependent on product loading, packaging material, gas composition and package/electrode configuration. The in-package ionization process has been demonstrated in a number of common packaging materials including cardboard, glass, LDPE, HDPE, PETE, polystyrene, rubber, tygon, and others. Scale-up of the system has facilitated treatment of air filled packages with an electrode gap of up to $10 \mathrm{~cm}$ with rapid processing times (Keener et al. 2010).

\section{Action of Plasma on microorganisms}

\section{Action on cell components and functions}

The use of sterilizing properties of plasma was first introduced towards the end of $60 \mathrm{~s}$, patented in 1968 (Menashi 1968) and first works with plasma made from oxygen were proposed in 1989. Thereafter, considerable research has been performed on the mechanism of microbial inactivation by plasma agents. The plasma agents contribute to the lethal action by interacting with the biological material. Nelson and Berger 
(1989) have shown that $\mathrm{O}_{2}$ plasma could be a very efficient biocidal against bacteria. Plasma treatment can effectively inactivate a wide range of micro-organisms including spores (Kelly-Wintenberg et al. 1999; Feichtinger et al. 2003; Lee et al. 2006) and viruses (Terrier et al. 2009). Effect of plasma can be quite selective, meaning tuneable between damage to pathogenic organisms without damage to the host, or activation of different pathways in different organisms (Dobrynin et al. 2009).

Low-pressure oxygen plasma has been shown to degrade lipids, proteins and DNA of cells (Mogul et al. 2003). The reactive species in plasma have been widely associated to the direct oxidative effects on the outer surface of microbial cells. As an example, commonly used oxygen and nitrogen gas plasma are excellent sources of reactive oxygen-based and nitrogen-based species, such as $\mathrm{O}^{\circ}, \mathrm{O}_{2}, \mathrm{O}_{3}, \mathrm{OH}^{\circ}, \mathrm{NO}^{\circ}, \mathrm{NO}_{2}$ etc. Atomic oxygen is potentially a very effective sterilizing agent, with a chemical rate constant for oxidation at room temperature of about $10^{6}$ times that of molecular oxygen (Critzer et al. 2007). These act on the unsaturated fatty acids of the lipid bilayer of the cell membrane, thereby impeding the transport of bio-molecules across it. The double bonds of unsaturated lipids are particularly vulnerable to ozone attack (Guzel-Seydim et al. 2004). Membrane lipids are assumed to be more significantly affected by the reactive oxygen species (ROS) due to their location along the surface of bacterial cell, which allows them to be bombarded by these strong oxidizing agents (Montie et al. 2002). The proteins of the cells and the spores are equally vulnerable to the action of these species, causing denaturation and cell leakage. Oxidation of amino acids and nucleic acids may also cause changes that result in microbial death or injury (Critzer et al. 2007).

Micro-organisms in plasma are exposed to an intense bombardment by the radicals most likely provoking surface lesions that the living cell cannot repair sufficiently faster. This may partially explain the observations wherein cells are in many cases destroyed very quickly. This process is termed "etching" (Pelletier 1992). The cell wall rupture has been additionally attributed by Laroussi et al., (2003) and Mendis et al., (2002) to electrostatic forces due to accumulation of charges at the outer surface of cell membranes. The morphological changes in $E$. coli cells treated with atmospheric plasma at $75 \mathrm{~W}$ for 2 min as observed under an electron microscope by (Hong et al. 2009), clearly revealed that the treated cells had severe cytoplasmic 
deformations and leakage of bacterial chromosome. These observations demonstrate the loss of viability of bacterial cells after plasma treatment.

An analogy between plasma and pulsed electric field has also been drawn to explain the action of plasma on the membranes (Pothakamury et al. 1995; Spilimbergo et al. 2003). It is well established that electroporation of membranes is induced by pulsed electric fields and it appears that plasma acts on similar lines inducing perforations in the membranes of micro-organisms (Sale and Hamilton 1967; Pothakamury et al. 1995; Wouters and Smelt 1997). In addition to generating pores, humid air plasma additionally provokes a marked acidification of the medium (Moreau et al. 2005; Moreau et al. 2007).

\section{Role of UV photons and charged particles}

The production of UV photons of different wavelengths has been proposed to be involved in dimerizing the thymine bases of DNA including that of spores (Munakata et al. 1991). The role of UV photons in bacterial death when they are submitted to a plasma treatment was reviewed in detail by (Boudam et al. 2006). Recently, by exclusion of reactive particles and spectral fractions of UV radiation from access to the spores Roth et al., (2010) revealed that UV-C radiation is the most effective inactivation agent in the plasma. Ultraviolet (UV) photons play a less important role in atmospheric pressure glow discharge (APGD) because they are easily absorbed by gas atoms and molecules at atmospheric pressure (Vleugels et al. 2005). The role of the charged particles in the bacterial inactivation process was recently investigated by Lu et al. (2009). Their work revealed that the charged particles play a minor role in the inactivation process when $\mathrm{He} / \mathrm{N}_{2}(3 \%)$ is used as working gas than when $\mathrm{He} / \mathrm{O}_{2}$ $(3 \%)$ is used. Also, they concluded that heat and UV play no or minor roles in the inactivation process. Similar results were earlier obtained by (Perni et al. 2007) who interplayed bacterial inactivation kinetics with optical emission spectroscopy, and identified oxygen atoms as major contributor in plasma inactivation with minor contributions from UV photons, $\mathrm{OH}$ radicals, singlet oxygen metastables and nitric oxide. Thus, a contradiction over the role of UV photons in plasma exists and future studies must be directed to get a clear picture. 


\section{Effect of process parameters}

The concentrations in which the plasma agents occur in plasma depend greatly on the device set-up (reactor geometry), operating conditions (gas pressure, type, flow, frequency and power of plasma excitation) and gas composition which affect their efficacy in a process when employed. To cite an example, the destructive efficiency of various gas plasma sources and temperatures on Bacillus spp. spores were compared by (Hury et al. 1998). This group demonstrated that oxygen-based plasma is more efficient than pure argon plasma. Another deciding criterion is whether the substrate to be sterilized is in direct contact with the plasma (Direct Exposure) or located remote from it (Remote Exposure) (Moisan et al. 2001; Laroussi 2005; Boudam et al. 2006). If exposed remotely, the quantum of heat transmitted to a sample is reduced, the charged particles do not play a role since they recombine before reaching the sample, and many of the short-lived neutral reactive species also do not reach the sample. Since, the components of the plasma are reactive and self-quenching, with a relatively short half-life, decreased time of flight would be expected to be one of the major factors in antimicrobial efficacy in this case (Niemira and Sites 2008).

By varying the process parameters involved in plasma generation, a multitude of mechanisms can be actuated which may act individually or synergistically. Nevertheless, the details of interaction of the different plasma agents with the different components of bacterial cells or spores are currently very limited. The interactions which occur between plasma agents and biological materials, ultimately leading to sterilization are still under investigation.

\section{Potential Applications}

The combination of highly energetic plasma species with a nonthermal treatment mode makes NTP particularly suited for decontamination in food processing settings (Yu et al. 2006). NTP has a myriad of potential applications for the food industry including the dry disinfection of food surfaces (like meat, poultry, fish and freshly harvested horticultural produce), granular and particulate foods (dried milk, herbs and spices) and sprouted seeds. There is a significant scope for NTP sterilization of the particulate foods, particularly after the ban of ethylene oxide gases. This technology 
has also been successfully applied for the surface sterilization of packaging material (Deilmann et al. 2008) and also their functional modification for imparting desired properties (Ozdemir et al. 1999; Güleç et al. 2006). A considerable body of data has already accumulated in recent years addressing the efficacy of NTP in inactivating microorganisms on the surfaces of abiotic materials such as glass and synthetic membranes.

\section{Treatment of raw and dried produce}

Escherichia coli, Salmonella typhimurium, Staphylococcus aureus, Listeria monocytogenes and Enterococcus faecalis are general food-borne pathogens that cause severe diseases and in some cases even death (Yun et al. 2010). Raw agricultural produce has frequently been implicated in disease outbreaks. Any treatment applied to ensure the microbiological safety of a food must be selected so as to minimize changes to its sensory, nutritional and functional properties (Manas and Pagán 2005). Conventionally, sterilization methods such as heat, chemical solutions and gases (for example ethylene oxide, hydrogen peroxide) are used for the surface disinfection of fruits, spices, nuts etc., which are often time consuming, damaging or have toxic residues (Muranyi et al. 2007). The pathogen inactivation effects of cold plasma potentially offer a treatment step for fresh produce to reduce the microbial load without adversely affecting the nutritional and other key characteristics. Recent, important and selected findings on plasma based inactivation of microorganisms have been summarized in Table 1.

Recent regulations by the US Food and Drug Administration (FDA) have required processors to achieve a $5 \log$ reduction in the numbers of the most resistant pathogens in their finished products. Interestingly, investigations at Commonwealth Scientific and Industrial Research Organization (CSIRO), Food and Nutritional Sciences, Australia, have also demonstrated up to $5 \log _{10}$ reductions of microorganisms after only a few seconds of exposure to cold plasma (Anonymous 2010). Similar results have also been published by many other researchers (Table 1). The ions of cold plasma can penetrate the cracks and crevices of even complex shaped bodies unlike other potential surface treatments such as UV light. Therefore the technology may act 
more effectively and efficiently over undulated or cracked surfaces such as those found on many foods like seeds, meat etc.

Selcuk et al. (2008) successfully decontaminated the seeds of tomato, wheat (Triticum durum), bean, chickpea, soybean, barley, oat, rye, lentil (Lens culinaris) and corn, contaminated with Aspergillus parasiticus 798 and Penicillium sp. to less than $1 \%$ of initial count depending on treatment times. The treatment times varied from $30 \mathrm{~s}$ to 30 min. This group employed a custom designed batch type low pressure cold plasma (LPCP) prototype unit operating under vacuum, using air and $\mathrm{SF}_{6}$ gases. The results suggest that in practical terms, after plasma treatment food qualities of wheat and beans were not affected or only marginally affected. It is worth mentioning that the seeds were found to be viable post plasma processing.

In a study of E. coli 12955, a non-pathogenic surrogate for Salmonella spp. inoculated onto almonds, Deng et al, (2006) reported a reduction of more than $4 \log$ CFU/ml. In this study sterilization was achieved by placing the almonds in a 10-mm gap between two plasma discharge electrodes and treating for $30 \mathrm{~s}(25 \mathrm{kV}, 2 \mathrm{kHz})$. Similarly, Niemira \& Sites (2008) significantly reduced the viable populations of Salmonella and E. coli $0157: \mathrm{H} 7$ inoculated on apple surfaces using cold plasma generated in a gliding arc. A 2.9 to $3.7 \log \mathrm{CFU} / \mathrm{ml}$ and 3.4 to $3.6 \log \mathrm{CFU} / \mathrm{ml}$ reduction of Salmonella Stanley and E. coli, respectively was observed. The authors reported the highest flow rate of the air (discharge medium) i.e. 40 litres/min, to be most effective.

\section{Control of biofilms and decontamination of processing surfaces}

Microorganisms are often embedded in the nutrient-rich environment of biofilms where they proliferate and are largely protected from external stresses such as direct attack of plasma species (Vleugels et al. 2005). The mechanisms involved in formation and behaviour of biofilms, deleterious effects associated with their presence and control strategies are reviewed in Simões et al. (2010). Biofilms are problematic in particular food industry sectors such as brewing, dairy processing, fresh produce, poultry processing and red meat processing (Simões et al. 2010; Chen et al. 2007; Frank et al. 2003; Jessen and Lammert 2003; Somers and Wong 2004). 
Plasma technology can also be exploited for possible applications in combating with the menace of biofilms that form on processing surfaces (Critzer et al. 2007). The US patent (\# 6096564, 2000) describes the invention by Denes et al. (2000) for the passivation of bacterial biofilm surfaces subjected to cold-plasma treatments. The patent claims that the exposure of the food processing surface with biological contamination thereon to an oxygen plasma results in sterilisation and cross-linked the biological contamination into a form which is resistant to further adhesion of bacteria and other biomaterials while cleansing and sterilizing areas of the substrate that are not covered by the biofilm. The inventors further suggested that a second step may be carried out to plasma mediate the deposit of an anti-fouling film using components that will provide macromolecular networks on the substrate with a desired structure which is resistant to bacterial adhesion. Vleugels and co-workers (2005) successfully inactivated biofilms forming Pantoea agglomerans (commonly associated with plant tissues) grown on synthetic membranes by two orders of log reduction in 10 min. They reported insignificant color change of the substrates viz. red, green and yellow bell pepper samples on exposure to glow discharge plasma. Abramzon et al. (2006) have reported almost $100 \%$ kill of Chromobacterium violaceum cells embedded in a four day old biofilms using a 100W RF high-pressure cold plasma jet. Distinct kinetic stages of inactivation have been reported in all the investigations suggesting different inactivation mechanisms, each of which might have been triggered by different plasma species or their different combinational/synergistic effects.

Survival of food-borne pathogens has been detected at a level of $10^{5} \mathrm{CFU} / \mathrm{cm}^{2}$ on stainless steel surfaces in a study by Kusumaningrum et al (2003). Deng et al. (2009) showed that cold gas plasmas have the potential to denaturize proteins attached to stainless steel. Gas plasmas could also be used to remove allergens from the surface of food processing equipment (Shama et al. 2009). Leipold et al. (2010) investigated the decontamination of a rotating cutting tool used for slicing in the meat industry by means of atmospheric pressure dielectric barrier discharge operated in air. Targeting for Listeria monocytogenes, this group inoculated the knife with Listeria innocua. The knife itself was used as a ground electrode in the experiment and a $5 \log$ reduction of L. innocua was obtained after $340 \mathrm{~s}$ of plasma operation. It was also reported that the temperature of the knife after treatment remained below $30^{\circ} \mathrm{C}$. Because the decontamination is achieved while the knife is in operation and this method allows 
reduced risk of cross contamination between separate batches of meat. Food manufacturers are increasingly investing in the cold plasma technology in order to kill the pathogens in the air and on the surfaces of processing plants (Brown 2010).

\section{Surface decontamination of eggs}

Salmonella spp. has been largely reported as a potential hazard for egg consumers and a need for alternative methods of decontaminations has been highlighted by Davies and Breslin (2003). The scientific literature has already evidenced several nonthermal approaches for the superficial decontamination of egg shells, including advanced oxidation procedures (AOP's) such as pulsed light technology (Hierro et al. 2009), ozone, UV radiation (Rodriguez-Romoand and Yousef 2005; Fuhrmann et al. 2010), slightly acidic electrolyzed water (Cao et al. 2009). These attempts are in extension to the failure of conventional techniques in efficient cleaning of the surface of eggs. Ragni and co-workers (2010) investigated the efficacy of resistive barrier discharge (RBD) plasma for decontamination of shell egg surfaces. Their work revealed a maximum reduction of 2.2-2.5 Log CFU/eggshell in Salmonella enteritidis levels following a 60-90 min of treatment at $35 \% \mathrm{RH}$. Further, the effectiveness of the treatments enhanced at a higher $\mathrm{RH}$ level of $65 \%$, where maximum declines of 3.8 and 4.5 Log CFU/eggshell were achieved after $90 \mathrm{~min}$ of exposure. Similar observations were made for Salmonella typhimurium, with an overall reduction of 3.5 Log CFU/eggshell, after 90 min treatment. The enhanced effects of increased RH on the efficiency of the treatments were explained in this study on the basis of the presence of oxygen species as detected in the discharge emission spectra. These results are at par with the UV and ozone treatments of eggs reported earlier (Rodriguez-Romoand and Yousef 2005). An important aspect of this study is that plasma treatment does not lead to any compromise with the cuticle quality, generally considered as the first mode of defence against microbial invasion. This was evidenced from the scanning electron microscopy (SEM) studies and dye uptake method. 
Food packaging materials are aimed at serving the functions of both preserving food and protecting it from deterioration, outside contamination or damage during distribution and storage. When not stored in proper conditions, packaging materials can get contaminated with microorganisms. These contaminants are transferred to food via packages, and their growth on food can result in economic losses because of spoilage (Turtoi and Nicolau 2007). In addition, they may cause public health concerns. In general, sterilization in bottling lines is achieved by means of oxidizing chemical germicidal liquids such as hydrogen peroxide, peracetic acid, ozonated water etc. (with or without mild heat treatment). The bottle is dipped or internally sprayed, optionally heated, rinsed and dried before being filled. Despite the effectiveness, this method generates liquid effluents, for which the cost of treatment gets added to that of the process. Moreover, in general, the management of water circuits always incurs a risk of development of inadvertent microbial contamination. Cold plasma has the potential to take over or complement the current chemical based sterilization methods for food packaging materials.

Current food-related applications of plasma are mostly limited to packaging industry and include sterilization of anti-fouling and printable surfaces and permeability reduction of polymers for carbon dioxide and oxygen (Schneider et al. 2005; Basaran et al. 2008). Low temperature gas plasma sterilization allows fast and safe sterilization of packaging materials such as plastic bottles, lids and films without adversely affecting the properties of the material or leaving any residues. This is also evident from the work of Muranyi et al. (2007) where Polyethylene terpthalate (PET) was used as the treatment medium with reported inactivation of several micro-organisms (Fig. 1). However, the type of materials is crucial and appropriate treatment conditions should be considered for achieving satisfactory inactivation levels (Yun et al. 2010). For example, no viable count has been detected after 90 and 120 s plasma treatments on plastic trays and only three decimal reductions on paper cups and aluminium foils under identical process parameters (Yun et al. 2010). Rostaing (2007) has patented an invention regarding a method for cold non-germicidal gas based plasma treatment of plastic bottles. This invention has added advantage of simultaneous deposition of diffusion barrier layer, thereby allowing integration of the sterilization and optionally impermeabilisation operations in the bottling line which extend from the moulding of the bottles till filling. Cold plasma for such applications 
can be generated either by distributed propagation of non-pulsed microwaves to an inside surface of the bottle or by a hollow cathode system adapted to the bottle and supplied with pulsed DC or radiofrequency voltage. Prior to this, Schmidt (2003) patented a system and method of applying energetic ions for sterilization of a container in which cold plasma is caused to get disposed near a surface to be sterilized, and the cold plasma is then subjected to a pulsed voltage differential for producing energized ions in the plasma.

Plasma deposition of heat sensitive materials such as vitamins, antioxidants and antimicrobials into the packaging material may be sought as potential alternative in the emerging field of antimicrobial and active packaging. Partial success has been achieved in depositing a plasma-processed vanillin film over red delicious apples by Fernandez-Gutierrez et al. (2010).

\section{Waste water treatment}

The surface water rules by the United States Environmental Protection Agency relating to chlorine and chlorine-derived products have stimulated operators (especially of poultry and meat industries, which are consumers of large volumes of water) to seek technologies that will assure discharge compliance (Kim et al. 2003). A potential method for generating plasma in liquids is by the application of high-voltage pulses to the gas-injected or sparged liquid and has opportunities in treating waste water from food industries, like poultry wash water (Rowan et al. 2007). This can be visualized as a combination of pulsed electric field and cold plasma and causes the generation of free radicals, free electrons, UV light, acoustic and shock waves, and electric fields at levels of 10-40 kV/cm (Espie et al. 2001). The application of highvoltage pulses to gas-sparged test liquids results in partial discharge activity and ionization of the gas, which leads to complete breakdown of the gas in the liquid medium (Rowan et al. 2007).

\section{Associated benefits and concerns:}

Cold plasma treatment of foods is a promising technology in that it acts rapidly, does not leave toxic residuals on processed parts or in the exhaust gas and the temperature 
rise can be kept to an acceptable level. The viability of grains and legumes has been shown to be preserved post plasma treatment with air and $\mathrm{SF}_{6}$ gases (Selcuk et al. 2008). Moreover, unlike pulsed light and gamma radiation, the shadow effect is minimized considerably using gas plasma methods as reactive species are produced in the whole chamber (Lassen et al. 2003; Goldman and Pruitt 1998). Contact angle (CA) measurements for nonthermal oxygen plasma treated lamb's lettuce have shown increased wettability of adaxial leaf surfaces after plasma exposure (Grzegorzewski et al. 2010a). Further, in this case a successive degradation of epicuticular waxes and cutin of the plant's epidermis was indicated by means of FTIR (ATR) and scanning electron microscopy (SEM). Above all, it can be conveniently operated in either batch or continuous mode. An aspect of the future of plasma technology is the possibility of pairing it with other decontamination processes such as pulsed-light treatment where synergistic effects may be more appreciable.

Studies on effect of nonthermal plasma on food components are scarce in literature. Based on experiments using low-pressure oxygen plasma it has been observed that a time- and structure-dependent degradation can be observed for different selected model flavonoids adsorbed on solid surfaces, which was attributed to plasmaimmanent reactive species such as $\mathrm{O}\left({ }^{3} \mathrm{P}\right), \mathrm{O}_{2}\left({ }^{1} \Delta_{\mathrm{g}}\right.$ and $\left.{ }^{1} \Sigma_{\mathrm{g}}{ }^{+}\right), \mathrm{O}_{3}$, or $\mathrm{OH}$ radicals (Grzegorzewski et al. 2010b). It has been observed in lamb's lettuce that pure compounds show a time-dependent degradation (flavonoids) or remain unchanged (phenolic acids) after exposure to oxygen plasma (Grzegorzewski et al. 2010a). Also, for the same model plant based food, a significant increase of protocatechuic acid, luteolin, and disometin has been recorded after $120 \mathrm{~s}$ treatment time, independent of the applied plasma driving voltage. The effect of the UV and radical species of plasma on the lipids and other sensitive constituents of the foods such as vitamins $\mathrm{C}$ and $\mathrm{E}$ (which are naturally occurring in most fruits and vegetables and many foods) still remains ambiguous. Suitability of plasma technology for treatment of high fat/ lipid containing and other sensitive foods (where chemical changes may be induced) is doubted. Products that have high lipid content would likely be affected by oxidation, resulting in formation of hydroxyl acids, keto acids, short-chain fatty acids and aldehydes etc. that cause off-flavours and odours. For these reasons meat products may not be ideal substrates for treatment with plasma (Critzer et al. 2007). For a full evaluation, additional issues concerning food quality must be considered and these 
include changes in nutrient content colour and textural qualities, toxic residues and other chemical changes (Vleugels et al. 2005). Research efforts must be undertaken to evaluate the projected cost of the treatment for large quantities of food commodities and also the safety of gases used before direct plasma techniques will become common in the food industry (Basaran et al. 2008).

\section{Conclusions}

The cold plasma technology is an emerging disinfection method that offers an exciting complementary or alternative, novel nonthermal approach for reducing the microbial populations on the raw or fresh produce surface and packaging materials. There may be several other applications in relation to food systems, which still remain unexplored. Various reactive species of plasma interact with the biological cells to cause permanent changes in them at cellular level and morphology, leading to inactivation. Although cold plasma technology is not yet used commercially on a large scale, the equipment should be readily scalable. Systems for large scale cold plasma treatment of food and related products using various energy sources and methods (like a multiplicity of microwave magnetrons) are already under development. This technology is increasingly finding acceptance among food processors for the surface sterilization and combating biofilm formation. The effect of cold plasma on the sensitive constituents of foods, mainly lipids, vitamins etc. have still some issues that need to be addressed and once this is achieved the technology will find wider applications and adaptation in food industries.

\section{Acknowledgements}

This work is supported by the IRCSET Embark Initiative.

\section{References:}

Abramzon N, Joaquin JC, Bray J, Brelles-Marino G (2006) Biofilm destruction by RF high-pressure cold plasma jet. Plasma Science, IEEE Transactions on 34 (4):1304-1309

Anonymous (2010) Technologies: Cool Plasma for Surface Decontamination. www.foodscience.afisc.csiro.au/cool-plasma.htm. Accessed 1st July 2010 
Azharonok V, Krat'ko L, Nekrashevich YI, Filatova I, Mel'nikova L, Dudchik N, Yanetskaya S, Bologa M (2009) Bactericidal action of the plasma of highfrequency capacitive and barrier discharges on microorganisms. Journal of Engineering Physics and Thermophysics 82 (3):419-426

Basaran P, Basaran-Akgul N, Oksuz L (2008) Elimination of Aspergillus parasiticus from nut surface with low pressure cold plasma (LPCP) treatment. Food Microbiology 25 (4):626-632. doi:DOI: 10.1016/j.fm.2007.12.005

Bellan PM (2006) Fundamentals of plasma physics. Cambridge University Press,

Boudam M, Moisan M, Saoudi B, Popovici C, Gherardi N, Massines F (2006) Bacterial spore inactivation by atmospheric-pressure plasmas in the presence or absence of UV photons as obtained with the same gas mixture. Journal of Physics D: Applied Physics 39:3494

Brown $H$ (2010) Get in for the pathogen kill with cold plasma technology. http://www.foodqualitynews.com/Innovation/Get-in-for-the-pathogen-killwith-cold-plasma-technology?nocount.

Cao W, Zhu ZW, Shi ZX, Wang CY, Li BM (2009) Efficiency of slightly acidic electrolyzed water for inactivation of Salmonella enteritidis and its contaminated shell eggs. International Journal of Food Microbiology 130 (2):88-93

Chen J, Rossman ML, Pawar DM (2007) Attachment of enterohemorrhagic Escherichia coli to the surface of beef and a culture medium. LWT-Food Science and Technology 40 (2):249-254

Cooper M, Fridman G, Staack D, Gutsol AF, Vasilets VN, Anandan S, Cho YI, Fridman A, Tsapin A (2009) Decontamination of surfaces from extremophile organisms using nonthermal atmospheric-pressure plasmas. Plasma Science, IEEE Transactions on 37 (6):866-871

Critzer F, Kelly-Wintenberg K, South S, Golden D (2007) Atmospheric plasma inactivation of foodborne pathogens on fresh produce surfaces. Journal of food protection 70 (10):2290

Davies R, Breslin M (2003) Investigations into possible alternative decontamination methods for Salmonella enteritidis on the surface of table eggs. Journal of Veterinary Medicine, Series B 50 (1):38-41

Deilmann M, Halfmann H, Bibinov N, Wunderlich J, Awakowicz P (2008) Lowpressure microwave plasma sterilization of polyethylene terephthalate bottles. Journal of Food Protection 71 (10):2119-2123

Denes AR, Somers EB, Wong ALC, Denes FS (2000) Plasma-aided treatment of surfaces against bacterial attachment and biofilm deposition. US Patent $6,096,564$, 
Deng X, Shi J, Kong M (2009) Protein destruction by a helium atmospheric pressure glow discharge: Capability and mechanisms. Journal of Applied Physics 101 (7):074701

Deng X, Shi J, Kong MG (2006) Physical mechanisms of inactivation of Bacillus subtilis spores using cold atmospheric plasmas. Plasma Science, IEEE Transactions on 34 (4):1310-1316

Dobrynin D, Fridman G, Friedman G, Fridman A (2009) Physical and biological mechanisms of direct plasma interaction with living tissue. New Journal of Physics 11:115020

Espie S, Marsili L, MacGregor SJ, Anderson JG (2001) Investigation of dissolved ozone production using plasma discharge in liquid. Pulsed power plasma science, Digest of Technical Papers 1:616-619

Feichtinger J, Schulz A, Walker M, Schumacher U (2003) Sterilisation with lowpressure microwave plasmas. Surface and Coatings Technology 174:564-569

Fernandez-Gutierrez SA, Pedrow PD, Pitts MJ, Powers J (2010) Cold AtmosphericPressure Plasmas Applied to Active Packaging of Apples. Plasma Science, IEEE Transactions on 38 (4):957-965

Frank JF, Ehlers J, Wicker L (2003) Removal of Listeria monocytogenes and poultry soil-containing biofilms using chemical cleaning and sanitizing agents under static conditions. Food Protection Trends 23 (8)

Fuhrmann H, Rupp N, Büchner A, Braun P (2010) The effect of gaseous ozone treatment on egg components. Journal of the Science of Food and Agriculture 90 (4):593-598. doi:10.1002/jsfa.3853

Goldman M, Pruitt L (1998) Comparison of the effects of gamma radiation and low temperature hydrogen peroxide gas plasma sterilization on the molecular structure, fatigue resistance, and wear behavior of UHMWPE. Journal of Biomedical Materials Research 40 (3):378-384. doi:10.1002/(sici)10974636(19980605)40:3<378::aid-jbm6>3.0.co;2-c

Gómez-López VM, Ragaert P, Debevere J, Devlieghere F (2007) Pulsed light for food decontamination: a review. Trends in Food Science \& Technology 18 (9):464473. doi:DOI: 10.1016/j.tifs.2007.03.010

Gould GW (2001) New processing technologies: an overview. Proceedings of the Nutrition Society 60 (04):463-474. doi:doi:10.1079/PNS2001105

Grzegorzewski F, Rohn S, Kroh LW, Geyer M, Schlüter O (2010a) Surface morphology and chemical composition of lamb's lettuce (Valerianella locusta) after exposure to a low-pressure oxygen plasma. Food Chemistry 122 (4):1145-1152

Grzegorzewski F, Rohn S, Quade A, Schröder K, Ehlbeck J, Schlüter O, Kroh LW (2010b) Reaction Chemistry of 1, 4 Benzopyrone Derivates in Non 
Equilibrium Low Temperature Plasmas. Plasma Processes and Polymers 7 (6):466-473

Güleç HA, SarIoglu K, Mutlu M (2006) Modification of food contacting surfaces by plasma polymerisation technique. Part I: Determination of hydrophilicity, hydrophobicity and surface free energy by contact angle method. Journal of Food Engineering 75 (2):187-195. doi:DOI: 10.1016/j.jfoodeng.2005.04.007

Guzel-Seydim ZB, Greene AK, Seydim AC (2004) Use of ozone in the food industry. Lebensmittel-Wissenschaft und-Technologie 37 (4):453-460. doi:DOI: 10.1016/j.lwt.2003.10.014

Havelaar AH, Brul S, de Jong A, de Jonge R, Zwietering MH, ter Kuile BH (2010) Future challenges to microbial food safety. International Journal of Food Microbiology $139 \quad$ (Supplement 1):S79-S94. doi:DOI: 10.1016/j.ijfoodmicro.2009.10.015

Hierro E, Manzano S, Ordóñez JA, de la Hoz L, Fernández M (2009) Inactivation of Salmonella enterica serovar Enteritidis on shell eggs by pulsed light technology. International Journal of Food Microbiology 135 (2):125-130. doi:DOI: 10.1016/j.ijfoodmicro.2009.07.034

Hong Y, Kang J, Lee H, Uhm H, Moon E, Park Y (2009) Sterilization effect of atmospheric plasma on Escherichia coli and Bacillus subtilis endospores. Letters in Applied Microbiology 48 (1):33-37

Hury S, Vidal D, Desor F, Pelletier J, Lagarde T (1998) A parametric study of the destruction efficiency of Bacillus spores in low pressure oxygen based plasmas. Letters in Applied Microbiology 26 (6):417-421

Jessen B, Lammert L (2003) Biofilm and disinfection in meat processing plants. International Biodeterioration \& Biodegradation 51 (4):265-269

Keener KM, Jensen JL, Valdramidis VP, Byrne E, Connolly J, Mosnier JP, Cullen PJ (2010) Decontamination of Bacillus subtilis spores in a sealed package using a non-thermal plasma system. Paper presented at the NATO Advanced Research Workshop- Plasma for bio-decontamination, medicine and food security, Jasna, Slovakia,

Kelly-Wintenberg K, Hodge A, Montie T, Deleanu L, Sherman D, Roth JR, Tsai P, Wadsworth L (1999) Use of a one atmosphere uniform glow discharge plasma to kill a broad spectrum of microorganisms. Journal of Vacuum Science \& Technology A: Vacuum, Surfaces, and Films 17:1539

Kim B, Yun H, Jung S, Jung Y, Jung H, Choe W, Jo C (2011) Effect of atmospheric pressure plasma on inactivation of pathogens inoculated onto bacon using two different gas compositions. Food Microbiology 28 (1):9-13. doi:DOI: 10.1016/j.fm.2010.07.022 
Kim J-G, Yousef AE, Khadre MA (2003) Ozone and its current and future application in the food industry. In: Advances in Food and Nutrition Research, vol Volume 45. Academic Press, pp 167-218

Kim K, Kim G, Hong YC, Yang SS (2010) A cold micro plasma jet device suitable for bio-medical applications. Microelectronic Engineering 87 (5-8):1177-1180

Klockow PA, Keener KM (2009) Safety and quality assessment of packaged spinach treated with a novel ozone-generation system. LWT-Food Science and Technology 42 (6):1047-1053

Korachi M, Gurol C, Aslan N (2010) Atmospheric plasma discharge sterilization effects on whole cell fatty acid profiles of Escherichia coli and Staphylococcus aureus. Journal of Electrostatics 68 (6):508-512. doi:DOI: 10.1016/j.elstat.2010.06.014

Kruk ZA, Yun HJ, Rutley DL, Lee EJ, Kim YJ, Jo C The effect of high pressure on microbial population and sensory characteristics of chicken meat. In: Proceedings of the 55th international congress of meat science and technology, Copenhagen, Denmark: Bella Center, 2009. pp 26-30

Kudra T, Mujumdar AS (2009) Advanced drying technologies. CRC Press,

Kusumaningrum H, Riboldi G, Hazeleger W, Beumer R (2003) Survival of foodborne pathogens on stainless steel surfaces and cross-contamination to foods. International Journal of Food Microbiology 85 (3):227-236

Laroussi M (2005) Low Temperature Plasma Based Sterilization: Overview and State of the Art. Plasma Processes and Polymers 2 (5):391-400

Laroussi M, Mendis D, Rosenberg M (2003) Plasma interaction with microbes. New Journal of Physics 5:41

Lassen KS, Nordby B, Grün R (2003) Optimization of a RF generated CF4/O2 gas plasma sterilization process. Journal of Biomedical Materials Research Part B: Applied Biomaterials 65 (2):239-244

Lee K, Paek K, Ju WT, Lee Y (2006) Sterilization of bacteria, yeast, and bacterial endospores by atmospheric-pressure cold plasma using helium and oxygen. Journal of Microbiology 44 (3):269-275

Leipold F, Kusano Y, Hansen F, Jacobsen T (2010) Decontamination of a rotating cutting tool during operation by means of atmospheric pressure plasmas. Food Control 21 (8):1194-1198

Liu F, Sun P, Bai N, Tian Y, Zhou H, Wei S, Zhou Y, Zhang J, Zhu W, Becker K (2010) Inactivation of Bacteria in an Aqueous Environment by a Direct Current, Cold Atmospheric Pressure Air Plasma Microjet. Plasma Processes and Polymers 7 (3 4):231-236 
Lu XP, Ye T, Cao YG, Sun ZY, Xiong Q, Tang ZY, Xiong ZL, Hu J, Jiang ZH, Pan $Y(2009)$ The roles of the various plasma agents in the inactivation of bacteria. Journal of Applied Physics 104 (5):053309

Manas P, Pagán R (2005) Microbial inactivation by new technologies of food preservation. Journal of applied microbiology 98 (6):1387-1399

Menashi WP (1968) Treatment of surfaces. US Patent 3,383,163,

Mendis D, Rosenberg M, Azam F (2002) A note on the possible electrostatic disruption of bacteria. Plasma Science, IEEE Transactions on 28 (4):13041306

Mogul R, Bol'shakov AA, Chan SL, Stevens RM, Khare BN, Meyyappan M, Trent JD (2003) Impact of low-temperature plasmas on Deinococcus radiodurans $\begin{array}{lllll}\text { and biomolecules. Biotechnology Progress } 19 & \text { (3):776-783. }\end{array}$ doi:10.1021/bp025665e

Moisan M, Barbeau J, Moreau S, Pelletier J, Tabrizian M, Yahia LH (2001) Lowtemperature sterilization using gas plasmas: a review of the experiments and an analysis of the inactivation mechanisms. International journal of Pharmaceutics 226 (1-2):1-21

Montie TC, Kelly-Wintenberg K, Roth JR (2002) An overview of research using the one atmosphere uniform glow discharge plasma (OAUGDP) for sterilization of surfaces and materials. Plasma Science, IEEE Transactions on 28 (1):41-50

Moreau M, Feuilloley M, Orange N, Brisset JL (2005) Lethal effect of the gliding arc discharges on Erwinia spp. Journal of applied microbiology 98 (5):1039-1046

Moreau M, Feuilloley M, Veron W, Meylheuc T, Chevalier S, Brisset JL, Orange N (2007) Gliding Arc Discharge in the Potato Pathogen Erwinia carotovora subsp. atroseptica: Mechanism of Lethal Action and Effect on MembraneAssociated Molecules. Applied and environmental microbiology 73 (18):5904

Munakata N, Saito M, Hieda K (1991) Inactivation action spectra of Bacillus subtilis spores in extended ultraviolet wavelengths (50-300 nm) obtained with synchrotron radiation. Photochemistry and photobiology 54 (5):761

Muranyi P, Wunderlich J, Heise M (2007) Sterilization efficiency of a cascaded dielectric barrier discharge. Journal of applied microbiology 103 (5):15351544

Nelson CL, Berger TJ (1989) Inactivation of microorganisms by oxygen gas plasma. Current Microbiology 18 (4):275-276

Niemira BA, Sites J (2008) Cold plasma inactivates Salmonella Stanley and Escherichia coli O157: H7 inoculated on golden delicious apples. Journal of Food Protection 71 (7):1357-1365 
Ozdemir M, Yurteri CU, Sadikoglu H (1999) Physical polymer surface modification methods and applications in food packaging polymers. Critical Reviews in Food Science and Nutrition 39 (5):457-477

Pelletier J (1992) La stérilisation par le procédé plasma (Sterilisation by plasma processing). Agressologie 33:105-110

Perni S, Liu DW, Shama G, Kong MG (2008b) Cold atmospheric plasma decontamination of the pericarps of fruit. Journal of Food Protection 71 (2):302-308

Perni S, Shama G, Hobman J, Lund P, Kershaw C, Hidalgo-Arroyo G, Penn C, Deng XT, Walsh J, Kong MG (2007) Probing bactericidal mechanisms induced by cold atmospheric plasmas with Escherichia coli mutants. Applied Physics Letters 90:073902

Perni S, Shama G, Kong MG (2008a) Cold atmospheric plasma disinfection of cut fruit surfaces contaminated with migrating microorganisms. Journal of Food Protection 71 (8):1619-1625

Petasch W, Räuchle E, Muegge H, Muegge K (1997) Duo-Plasmaline -- a linearly extended homogeneous low pressure plasma source. Surface and Coatings Technology 93 (1):112-118. doi:10.1016/s0257-8972(97)00015-7

Pothakamury UR, Monsalve-Gonz lez A, Barbosa-Cánovas GV, Swanson BG (1995) Inactivation of Escherichia coli and Staphylococcus aureus in model foods by pulsed electric field technology. Food Research International 28 (2):167-171

Ragni L, Berardinelli A, Vannini L, Montanari C, Sirri F, Guerzoni ME, Guarnieri A (2010) Non-thermal atmospheric gas plasma device for surface decontamination of shell eggs. Journal of Food Engineering 100 (1):125-132

Rastogi N, Raghavarao K, Balasubramaniam V, Niranjan K, Knorr D (2007) Opportunities and challenges in high pressure processing of foods. Critical Reviews in Food Science and Nutrition 47 (1):69-112

Rodriguez-Romoand LA, Yousef AE (2005) Inactivation of Salmonella enterica serovar Enteritidis on shell eggs by ozone and UV radiation. Journal of Food Protection 68 (4):711-717

Rostaing J (2007) Method for Cold Plasma Treatment of Plastic Bottles and Device for Implementing Same. US Patent App. 20,090/304,950,

Roth S, Feichtinger J, Hertel C (2010) Characterization of Bacillus subtilis spore inactivation in low pressure, low temperature gas plasma sterilization processes. Journal of applied microbiology 108 (2):521-531

Rowan N, Espie S, Harrower J, Anderson J, Marsili L, MacGregor S (2007) Pulsedplasma gas-discharge inactivation of microbial pathogens in chilled poultry wash water. Journal of Food Protection 70 (12):2805-2810 
Sale A, Hamilton W (1967) Effects of high electric fields on microorganisms:: I. Killing of bacteria and yeasts. Biochimica et Biophysica Acta (BBA)-General Subjects 148 (3):781-788

Sampedro F, Rodrigo M, Martinez A, Rodrigo D, Barbosa-Cánovas G (2005) Quality and safety aspects of PEF application in milk and milk products. Critical Reviews in Food Science and Nutrition 45 (1):25-47

Schmidt JA (2003) System and method of applying energetic ions for sterilization. US Patent 6,667,007,

Schneider J, Baumgärtner K, Feichtinger J, Krüger J, Muranyi P, Schulz A, Walker M, Wunderlich J, Schumacher U (2005) Investigation of the practicability of low-pressure microwave plasmas in the sterilisation of food packaging materials at industrial level. Surface and Coatings Technology 200 (1-4):962966

Schulz A, Feichtinger J, Krüger J, Walker M, Schumacher U Spectroscopic investigations on silicon nitride deposition with the Plasmodul@. Surface and Coatings Technology 174-175:947-951. doi:10.1016/s0257-8972(03)00535-8

Selcuk M, Oksuz L, Basaran P (2008) Decontamination of grains and legumes infected with Aspergillus spp. and Penicillum spp. by cold plasma treatment. Bioresource Technology 99 (11):5104-5109

Shama G, Bayliss D, Perni S, Kong MG (2009) Applications of cold atmospheric gas plasmas for microbial decontamination in the food industry. Paper presented at the BFE 2009: Proceedings of the International Conference on Bio and Food Electrotechnologies, Compiegne, France,

Simões M, Simões LC, Vieira MJ (2010) A review of current and emergent biofilm control strategies. LWT-Food Science and Technology 43 (4):573-583

Somers EB, Wong ACL (2004) Efficacy of two cleaning and sanitizing combinations on Listeria monocytogenes biofilms formed at low temperature on a variety of materials in the presence of ready-to-eat meat residue. Journal of Food Protection 67 (10):2218-2229

Spilimbergo S, Dehghani F, Bertucco A, Foster NR (2003) Inactivation of bacteria and spores by pulse electric field and high pressure $\mathrm{CO} 2$ at low temperature. Biotechnology and bioengineering 82 (1):118-125

Terrier O, Essere B, Yver M, Barthélémy M, Bouscambert-Duchamp M, Kurtz P, VanMechelen D, Morfin F, Billaud G, Ferraris O, Lina B, Rosa-Calatrava M, Moules V (2009) Cold oxygen plasma technology efficiency against different airborne respiratory viruses. Journal of Clinical Virology 45 (2):119-124. doi:DOI: 10.1016/j.jcv.2009.03.017

Tiwari BK, O'Donnell CP, Cullen PJ (2009) Effect of non thermal processing technologies on the anthocyanin content of fruit juices. Trends in Food Science \& Technology 20 (3-4):137-145. doi:DOI: 10.1016/j.tifs.2009.01.058 
Turtoi M, Nicolau A (2007) Intense light pulse treatment as alternative method for mould spores destruction on paper-polyethylene packaging material. Journal of Food Engineering 83 (1):47-53

Vleugels M, Shama G, Deng XT, Greenacre E, Brocklehurst T, Kong MG (2005) Atmospheric plasma inactivation of biofilm-forming bacteria for food safety control. Plasma Science, IEEE Transactions on 33 (2):824-828

Von Keudell A, Awakowicz P, Benedikt J, Raballand V, Yanguas Gil A, Opretzka J, Flötgen C, Reuter R, Byelykh L, Halfmann H (2010) Inactivation of Bacteria and Biomolecules by Low Pressure Plasma Discharges. Plasma Processes and Polymers 7 (3 4):327-352

Wouters PC, Smelt JPPM (1997) Inactivation of microorganisms with pulsed electric fields: potential for food preservation. Food Biotechnology 11 (3):193-229

Yoon YH, Ryu KH (2007) Atmospheric plasma surface treatment equipment. News Information Chemical Engineering 25:268-271

Yu H, Perni S, Shi J, Wang D, Kong M, Shama G (2006) Effects of cell surface loading and phase of growth in cold atmospheric gas plasma inactivation of Escherichia coli K12. Journal of applied microbiology 101 (6):1323-1330

Yun H, Kim B, Jung S, Kruk ZA, Kim DB, Choe W, Jo C (2010) Inactivation of Listeria monocytogenes inoculated on disposable plastic tray, aluminum foil, and paper cup by atmospheric pressure plasma. Food Control 21 (8):11821186. doi:DOI: 10.1016/j.foodcont.2010.02.002 
Table 1. Recent findings in the area of nonthermal plasmas for inactivation of microorganisms and spores.

\begin{tabular}{|c|c|c|c|c|}
\hline Organism & Plasma conditions & $\begin{array}{l}\text { Treatment } \\
\text { surface/ medium }\end{array}$ & Salient result & References \\
\hline $\begin{array}{l}\text { Escherichia coli, } \\
\text { Staphylococcus aureus }\end{array}$ & $\begin{array}{l}\text { Atmospheric plasma } \\
\text { corona discharge, with } \\
\text { high voltage }(20 \mathrm{kV}) \mathrm{DC} \\
\text { power supply }\end{array}$ & On agar plates & $\begin{array}{l}\text { Changes of } \mathrm{pH} \text { levels from alkaline to acid, upon } \\
\text { plasma application to bacteria in water, does not } \\
\text { play a predominant role in cell death. }\end{array}$ & $\begin{array}{l}\text { Korachi et al. } \\
(2010)\end{array}$ \\
\hline Staphylococcus aureus & $\begin{array}{l}\text { DC cold- atmospheric- } \\
\text { pressure plasma microjet } \\
\text { with compressed air as } \\
\text { the working gas }\end{array}$ & $\begin{array}{l}\text { Aqueous } \\
\text { suspensions of the } \\
\text { organism }\end{array}$ & $\begin{array}{l}\text { First } 10 \text { min treatment led to insignificant } \\
\text { inactivation. After } 16 \text { min } S \text {. aureus was } \\
\text { completely inactivated. Effective inactivation of } \\
\text { S. aureus was found to start after the pH values } \\
\text { decreased to about } 4.5 \text {. }\end{array}$ & Liu et al. (2010) \\
\hline $\begin{array}{l}\text { Bacillus atrophaeus, } \\
\text { Geobacillus } \\
\text { sterathermophilus, } \\
\text { Clostridium sporogenes, } \\
\text { Kocuria rhizophila, } \\
\text { Staphylococcus aureus, } \\
\text { Aspergillus niger }\end{array}$ & $\begin{array}{l}\text { low- pressure } \\
\text { inductively-coupled } \\
\text { plasma (ICP) with } \\
\text { different mixtures of } \\
\text { gases }\end{array}$ & $\begin{array}{l}\text { Glass substrates } \\
\text { and silicon wafers } \\
\text { coated with the } \\
\text { organism by } \\
\text { spraying. }\end{array}$ & $\begin{array}{l}\text { All the organisms were found to be reduced by at } \\
\text { least } 4 \text { orders of magnitude under optimized low- } \\
\text { pressure argon plasma. Efficiency of inactivation } \\
\text { was variable for different strains of a given } \\
\text { species. }\end{array}$ & $\begin{array}{l}\text { Von Keudell et al. } \\
\text { (2010) }\end{array}$ \\
\hline Bacillus subtilis & $\begin{array}{l}\text { Oxygen and nitrogen } \\
\text { treated using } 8 \text { Duo- } \\
\text { Plasmalines driven by } \\
\text { microwaves power }\end{array}$ & $\begin{array}{l}\text { Microscopic slides } \\
\text { stacked with spores }\end{array}$ & $\begin{array}{l}\text { Plasma treatment of the spores caused release of } \\
\text { DPA, generation of auxotrophic mutants, } \\
\text { reduction in Kat X activity and damage to DNA. } \\
\text { A biphasic model for the inactivation kinetics was } \\
\text { proposed. }\end{array}$ & Roth et al. (2010) \\
\hline
\end{tabular}




\section{High-frequency}

\section{Escherichia coli, Bacillus} subtilis, Candida albicans, and Staphylococcus aureus

\section{Influenza viruses \\ (RSV, hPIV-3 and A (H5N2) )}

\section{Escherichia coli KCTC1039}

Bacillus subtilis

capacitive discharge $(0.4$

Deinococcus radiodurans

Escherichia coli type 1 Saccharomyces cerevisiae Gluconobacter liquefaciens Listeria monocytogenes torr) and barrier

discharge (0.4-0.5 torr)

in air excited at

commercial frequency of

\section{$5.28 \mathrm{MHz}$}

Air subjected to highenergy deep-UV light using Biozone scientific COP generator

Helium and Oxygen based electric discharge plasma produced at a radio frequency $(\mathrm{RF})$ of $13.56 \mathrm{MHz}$

Dielectric Barrier Discharge (DBD)

Glass plate and petri dish

Air

Dried cells and endospore suspension on a cover-glass

\section{Cells dried in} laminar flow hood and cells suspended in distilled water

Cold atmospheric plasma plume generated by an AC voltage of 8 $\mathrm{kV}$ at $30 \mathrm{kHz}$

Inoculated membrane filters and inoculated fruit surfaces
The most probable sterilization agents of the plasma generated were established to be "hot" and "cold" OH radicals, the excited electrically neutral $\mathrm{N}_{2}$ and $\mathrm{O}_{2}$ molecules, and the UV plasma radiation.

More than $99.8 \%$ reduction of influenza virus A (H5N2).

Terrier et al. (2009)

Treated cells had severe cytoplasmic deformations and leakage of bacterial chromosome. UV from the plasma only slightly affected the viability of the spores.

$4 \log$ reduction of CFU count in $15 \mathrm{~s}$ of the extremophile organism suspended in distilled

Azharonok et al. (2009) water. This was attributed to the fact that plasma compromises the integrity of the cell membrane of the organism.

Efficacy of inactivation was markedly reduced for microorganisms on the cut surfaces than on filters due to the migration of microorganisms from the exterior of the fruit tissue to its interior and not

Perni et al. (2008a)

oper et al. (2009) quenching of reactive plasma species. 
Escherichia coli O157:H7 Salmonella Stanley

Gliding Arc plasma

Aspergillus parasiticus and Aflatoxins

Escherichia coli

Saccharomyces cerevisiae

Pantoea agglomerans

Gluconacetobacter

liquefaciens

Escherichia coli $\mathrm{O} 157: \mathrm{H} 7$

Salmonella sp.

Listeria monocytogenes

Escherichia coli

Air gases and $\mathrm{SF}_{6}$ plasma using total applied power of

Cold atmospheric AC voltage (variable $12 \mathrm{kV}$ and $16 \mathrm{kV}$ ) frequency

Air in a Dielectric
On agar plates and inoculated onto surfaces of Golden

Delicious apples approximately $300 \mathrm{~W}$

Hazelnuts, Peanuts, and Pistachio nuts plasma generated by an

Pericarps of mangoes and melons

One atmosphere uniform glow discharge plasma (OAUGDP) operated at $9 \mathrm{kV}$ power and $6 \mathrm{kHz}$ discharge chamber
Apples,

Cantaloupe and

Lettuce

Inactivation was observed in all the cases. Extent of $\log$ reduction varied with the organisms.

Critzer et al. (2007)

Raw almonds

Up to $5 \log$ reduction observed
Bacterial inactivation was shown to be a function of flow rate and duration of exposure.

$\mathrm{SF}_{6}$ plasma application was more effective with a 5 -log decrease in fungal population for the same duration as air gases plasma. $20 \mathrm{~min}$ air gases plasma treatment resulted in a $50 \%$ reduction in total aflatoxins (AFB1, AFB2, AFG1, and AFG2), while only a $20 \%$ with $\mathrm{SF}_{6}$ plasma treatment. No significant organoleptic changes were observed.

Niemira and Sites (2008)

Basaran et al. (2008)

S. cerevisiae was the most resistant amongst all test organisms. An increase in the applied voltage led to more efficient production of reactive plasma species (oxygen atoms) which was

Perni et al. (2008b) attributed for better inactivation. 


\section{Escherichia coli NCTC}

9001, Campylobacter jejuni ATCC 33560 ,

Campylobacter coli ATCC 33559, Listeria

monocytogenes NCTC 9863 ,

Salmonella enterica serovar

Enteritidis ATCC 4931,

Salmonella enterica serovar

Typhimurium ATCC 14028, and Bacillus cereus NCTC

11145 endospores.

Aspergillus niger,

Bacillus atrophaeus,

Bacillus pumilus,

Clostridium botulinum type

A, Clostridium sporogenes,

Deinococcus radiodurans,

Escherichia coli,

Staphylococcus aureus,

Salmonella mons

Biofilms produced by

Chromobacterium

violaceum
Pulsed plasma gas

discharge (PPGD) using

high-voltage pulses

(with 40-kV DC

capacitor) in a coaxial

treatment chamber.

Different treatment

gases viz. nitrogen,

carbon dioxide, oxygen

and air as sparging

Cascaded dielectric

barrier discharge with

air as the plasma gas

PET foils
Poultry wash water at $4{ }^{\circ} \mathrm{C}$
Rapid reductions in microbial numbers (by $\leq 8$

$\log \mathrm{CFU} / \mathrm{ml})$. Use of oxygen alone produced the greatest reductions. In general gram negative test bacteria were more susceptible.
Highest count reduction was observed for the vegetative cells with at least $6.6 \log _{10}$ with in $1 \mathrm{~s}$. Aspergillus niger was the most resistant test strain with an inactivation rate of about $5 \log _{10}$ in $5 \mathrm{~s}$.
Rowan et al.

(2007)
Muranyi et al.

(2007)
RF high pressure cold plasma jet using Atomflo 250 reactor with $100 \mathrm{~W}$ RF power supply using $\mathrm{He}$ and $\mathrm{N}_{2}$ gas

Biofilms produced in 96-well polystyrene microplates
A 10 min plasma treatment was able to kill almost $100 \%$ of the cells. A complex, biphasic model of inactivation was observed.
Abramzon et al. (2006) 


\section{Bacillus subtilis spores}

Escherichia coli $\mathrm{K} 12$
Dielectric-barrier discharge (DBD) with pure helium or heliumoxygen mixture.

Atmospheric plasma plume generated using He gas with a peak voltage of $6 \mathrm{kV}$
Polycarbonate membranes, supported by a layer of technical no.3 agar in a petridish.

\section{E. coli cells} deposited on surface of membrane filters
Spore inactivation was mostly induced by the reactive oxygen species with the heat, UV photons, electric field and charged particles; all making minor contributions. Atmospheric-helium plasma plume was more effective than atmospheric-helium-oxygen plasma plume.

SEM revealed severe loss in structural integrity of plasma-treated cells. Survival of E. coli cells was found to depend on the cell surface density, as it affects plasma penetration depth. Physiological resistance to plasma inactivation. 


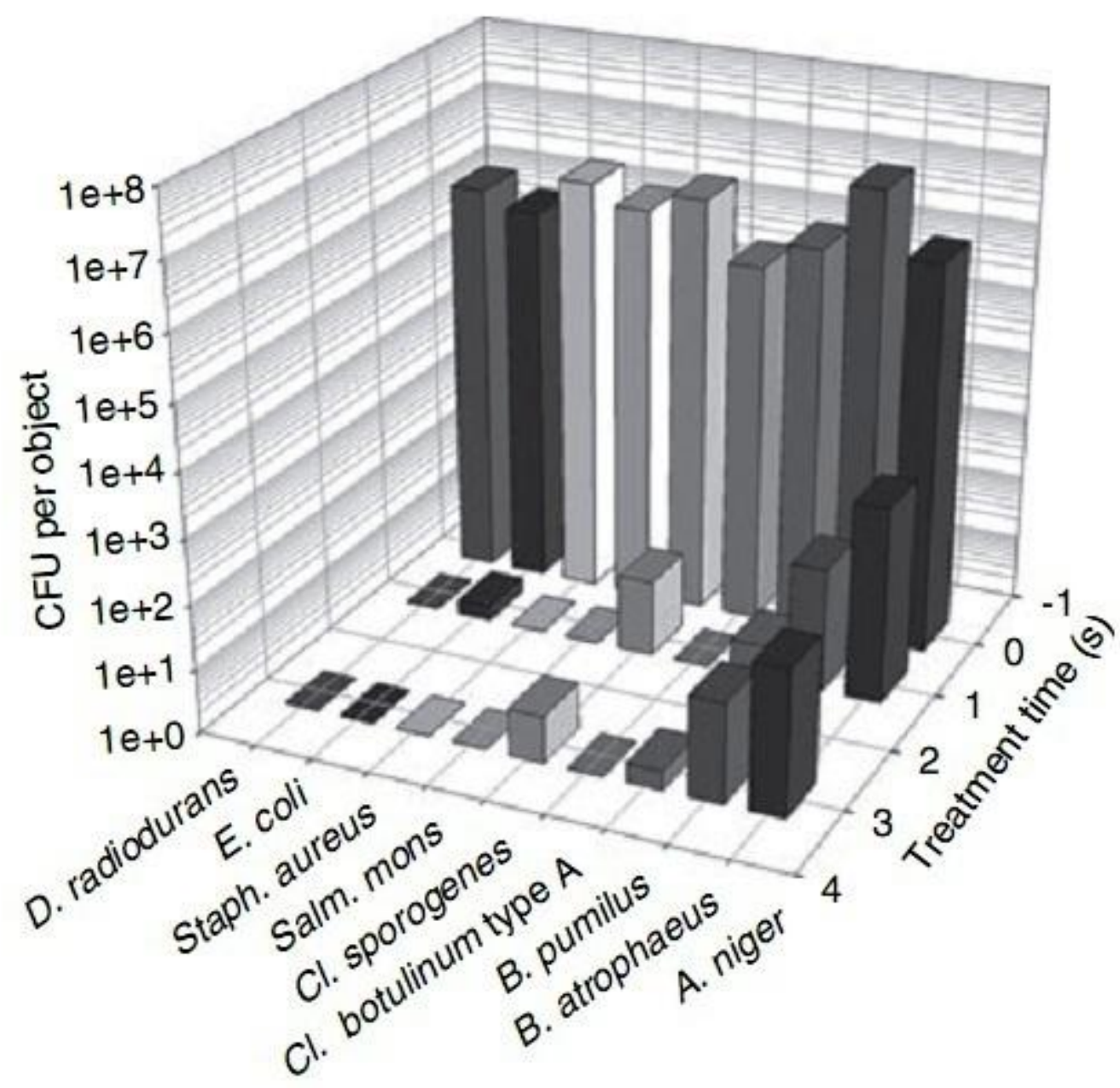

Fig. 1. Time-dependent inactivation of different test strains on PET foils with the CDBD equipped with a $282 \mathrm{~nm}$ excimer flat lamp. For comparison, the initial bacterial count should be in the range of approx. $10^{6} \mathrm{CFU}$ per sample. Process gas was laboratory air and input power was kept at about 130W (Muranyi et al. 2007). 